\title{
AUTOMATION OF THE DESIGN OF THE ANCHORAGE SYSTEM TAKING INTO ACCOUNT THE GEOMECHANICAL STATE OF THE MASSIF AND MINING DEVELOPMENT SCHEMES
}

\author{
Vladimir Demin, Alexander Tomilov ${ }^{1}$, Bakhyt Sultanova \\ Karaganda State Technical University, 100027, Karaganda, Kazakhstan
}

\begin{abstract}
The article presents the system for the automation of the design of the anchorage, which regulates the calculation of the required parameters of the fasteners for the fastening of the fastening system. The main factors affecting the operation of the anchor support are grouped in the following way: mining and geological conditions, technical characteristics of the anchor support, geomechanical conditions for conducting and operating the mine workings. Mining and geological conditions for carrying out excavations include: physical and mechanical properties of rocks, the category of roof stability, fracturing, etc. Technical characteristics of the anchor support: material of the rod, filler, filling completeness, etc. Conditions (geomechanical) of carrying out and exploitation of the mine workings: the depth of the conduct, the location relative to the zone of influence of the cleaning works, the location relative to the waste zone, etc. As a result of calculations the program gives out the basic parameters of the anchor support, which coincide with the parameters adopted by the passport.
\end{abstract}

\section{Introduction}

In increasing the productivity of mining production, it is very important to solve the problem of improving the methods and means of fastening and maintaining the mine workings sustainably. The cost of excavation workings is quite large and amounts to $15-22 \%$ of the prime cost of coal mining.

High costs also require qualitative maintenance of preparatory workings, both for their repair before and after commissioning of cleaning faces that reach $15-22 \%$ of the cost of carrying out mine workings [1].

At existing depths of development of $600-851 \mathrm{~m}$ of coal basins with modern supports it is very difficult to achieve maintenance-free workings.

One of the effective ways to improve the state of excavations and save material resources is the use of a combined anchor-frame support.

\footnotetext{
${ }^{1}$ Corresponding author: tom44487@mail.ru
} 
To date, the world practice has accumulated sufficient experience in applying the technology of erecting anchorage in mine workings. However, studies show that the condition of mine workings, especially excavations, is not always satisfactory.

In the solution of these issues, the weakest link is insufficient automation of the process of calculating optimal technological schemes for conducting mine workings with anchor and combined supports under different mining and geological and mining conditions of their development.

The content of the research is as follows:

1) In optimizing the mathematical apparatus by calculation:

- Combined support (anchors with frames).

- The length and density of anchoring rope anchors in the anchoring and combined fastening of mine workings.

- Anchoring of the mating of mine workings, taking into account the various conditions of the mine workings: work-up, work-in-hand, reference rock pressure, increased rock pressure, lava influence, the impact of close workings, preservation for reuse behind the bottom line.

2) In the development and creation of a computer system with:

- The possibility of taking into account the emerging strained-deformed state of the rock massif, permissible limiting deformation of the roof rocks.

- Possibility of using two-and three-level fastening, mixed mounting of mine workings.

- A modular organization of the system, the logical model of which is represented by the subsystem of the user interface, the subsystem for the formation of the information model, the subsystem of mathematical calculations, the drawing and formation of the results of calculations of the anchorage system and the output subsystem.

Improvement of the method for calculating the anchor support parameters, in terms of its automation, allows to significantly reduce the time for designing anchorage systems and increase the number of options considered, as well as to exclude the "human" factor in the calculation of technological fastening schemes for mine workings.

\section{Methods of solution}

The aim of the study is to increase the efficiency of the work carried out in coal mines, by reducing the time for calculating the optimal technological schemes for anchoring the anchor and combined supports for various mining and geological and mining-technological conditions for mining the mine workings of coal mines.

To achieve this goal, the following tasks were accomplished:

1) The current state of problems in the use of anchorage of mine workings in the world and in the Karaganda coal basin, such as:

- Analysis of factors affecting the effectiveness of the use of anchor support in mine workings.

- Study of stability of contours of preparatory excavations taking into account their straineddeformed state depending on mining and geological factors.

- Study of the stress-strain state of excavation workings depending on the influence of technological factors.

2) The mathematical apparatus for calculating anchor and combined technological schemes for managing the state of the array and improving the quality of anchored rocks adaptable to changing mining technological conditions is optimized:

- Anchor support.

- Combined support (anchor + frame). 
- The length and density of anchoring rope anchors in the anchoring and combined fastening of mine workings.

Anchoring of mating connections of mine workings, taking into account:

- Different conditions for carrying out mine workings: work-up, work-in-progress, bearing rock pressure, increased rock pressure, lava influence, the impact of close workings, conservation for reuse behind the bottom line.

- Permissible lowering of the contours of the development, the arising strained-deformed state of the rock massif, permissible limiting deformation of the roof rocks, the possibility of two- and three-level fastening.

3) An automated system for designing technological schemes for the development of rocks for various mining and geological and mining conditions has been developed, which regulates the calculation of the required parameters of fastening passports, the construction of a fastening system, and the validation of design:

- Digital models for calculation of anchor and combined supports taking into account various mining-geological and mining-technical conditions for conducting mine workings.

- Model and information support of the automated system for designing technological schemes for mining workings, with the following capabilities:

- Taking into account the emerging strained-deformed state of the rock massif, permissible limiting deformation of the roof rocks.

- Use of two- and three-level fastening, mixed mounting of mine workings.

The architecture of the computer system for the automation of the design of the anchorage system, represented by a multi-user database and a modular structure of program modules, its logical model consists of a subsystem of the user interface; subsystems of mathematical calculations; subsystems of tracing and the subsystem of formation of results of calculating anchor support parameters. And also the module for the formation of technological passports of anchorage of excavations, taking into account mining and geological and mining conditions of operation.

\section{The choice of influencing factors and the structure of the initial data}

In reality, an array of rocks is a very complex environment, formed under the influence of all sorts of geological factors. Mechanical properties of rocks in the array vary among themselves in a wide range. The property of the processes occurring in the mountain mass around the mine workings, including the coal mine, apart from the mechanical properties of the rocks, is significantly affected by their stress state caused by man-made processes in mining operations.

Since it is very difficult to take into account the diversity of the properties of the rock massif, various mechanical models are used to study it. They reflect only the main essential properties of rocks and discard all other factors. The main properties include strength and deformation characteristics (elasticity, plasticity, brittleness), continuity, isotropy and homogeneity of the body under study.

In theoretical studies, the following basic types of models are used to study the interaction of rock massif with the support of rock mining: elastic, rigid-plastic, elastoplastic, elastoplastic non-uniform, elastic-viscous, viscoplastic.

The effectiveness of the use of anchor support is greatly affected by the correctness of accounting for all influencing factors. But to take into account all the factors for determining the parameters of the anchor support is almost impossible. Therefore, the main factors that have the greatest influence are used in the calculations. 
The peculiarity of the anchor support is that, unlike the metal frame support, the anchor support from the moment of its installation works with the array as a single system. Bearing capacity of the array of installed anchors increase due to the cross-linking of rock layers between each other. That is why, the main load from the rocks located above the mine workings will be an array, fixed with an anchor support.

[2]:

Group, the main factors that determine the work of the anchor support can be as follows

- Mining and geological conditions for conducting mine workings.

- Technical parameters of the anchor support.

- Geomechanical conditions of mining operation and its operation.

Mining-geological conditions for conducting mine workings can be grouped as follows:

- Physical and mechanical properties of rocks.

- Categories of stability of the roof of mine workings.

- Fracture of rocks.

Technical properties of the anchor support include:

- Anchor rod material.

- Filler.

- Completeness of filling, etc.

Geomechanical conditions for carrying out and operating the mine workings can be represented by the following set of properties:

- The depth of the mine workings.

- The location of the mine in relation to the zone of influence of the cleaning works.

- The location of the development with respect to the worked-out zone.

It is very difficult to take into account the last group of factors, because these factors influence the stability of mine workings. Therefore, depending on the geological and geo mechanical conditions, we will highlight the following most important types of calculations for the mine workings:

- Mine workings and mattings, which are carried out and maintained outside the zone of influence of clearing works.

- For main mine workings and mattings supported in the reference pressure zone with a width of $>0.05 \mathrm{~m}$ and $<15 \mathrm{~m}$.

- For excavation workings extinguished behind lava.

- For excavation workings, protected entirely with a width $>15 \mathrm{~m}$ and extinguished after adjacent lava.

- For excavation workings, protected entirely by a width of $2.5-3.0 \mathrm{~m}$ of the thickness of the formation, and then extinguished after adjacent lava.

- Mine workings, conducted in a cut-off to the worked out space.

- Mounting chambers.

The method of calculating the anchor is as follows.

Depending on the initial data for specific mining and geological and mining conditions for calculating the anchor support as a criterion for the intensity of the rock pressure, we take the calculated displacements of the roof rocks with the anchor support.

To determine the parameters of the anchorage and the choice of reinforcement, depending on the calculated displacements, we distinguish the following intervals of intensity of the manifestation of rock pressure:

- At estimated offsets of roof rocks $<50 \mathrm{~mm}$ : small rock pressure.

- At estimated offsets of roof rocks $>50$ and $<200 \mathrm{~mm}$ : mountain pressure of medium intensity.

- At estimated offsets of roof rocks> $200 \mathrm{~mm}$ : intensive rock pressure. 
In the case of a small rock pressure at the calculated displacements of the roof rocks $<50$ $\mathrm{mm}$, the resistance of the anchor support and the length of the anchors installed in the bottom hole are taken from Table 1 [3], depending on the class of roof rocks.

Table 1. Stability classes of rocks.

\begin{tabular}{|c|c|c|}
\hline $\begin{array}{c}\text { Grade I } \\
\text { Rocks of the roof are unstable }\end{array}$ & $\begin{array}{c}\text { Grade II } \\
\text { Roofs of medium stability }\end{array}$ & $\begin{array}{c}\text { Grade III } \\
\text { Roof resilient rocks } \\
\end{array}$ \\
\hline $\begin{array}{l}\text { The roof rock collapses after } \\
\text { exposure at a distance from the } \\
\text { face to } 1 \mathrm{~m}\end{array}$ & $\begin{array}{l}\text { The stability of the roof is } \\
\text { preserved when the roof is } \\
\text { exposed at a distance from the } \\
\text { face of } 1 \text { to } 3 \mathrm{~m}\end{array}$ & $\begin{array}{l}\text { The stability of the roof is } \\
\text { preserved when exposed at a } \\
\text { distance of more than } 3 \mathrm{~m} \\
\text { from the face }\end{array}$ \\
\hline $\begin{array}{l}\text { Thin-layered and fissured } \\
\text { mudstones predominate }\end{array}$ & $\begin{array}{l}\text { Layered low-cracked siltstones } \\
\text { and sandstones prevail }\end{array}$ & $\begin{array}{l}\text { Non-inter bedded sandstones, } \\
\text { marls predominate }\end{array}$ \\
\hline $\begin{array}{l}\text { Average design compressive } \\
\text { strength of rocks }(R c) \leq 30 \\
\mathrm{MPa}\end{array}$ & $30<R c \leq 80 \mathrm{MPa}$ & $R c>80 \mathrm{MPa}$ \\
\hline
\end{tabular}

For the II class of the roof rocks, the resistance of the anchor support is taken as for Class I, and the length of the anchors can be reduced by $21 \%$.

For roofing types I and III classes, the reduction in the length of anchors is possible by $10 \%$ or $21 \%$, but it is necessary to increase the density of the anchorage installation or to apply anchors of increased load capacity, and the design resistance of the anchor support must be increased by 30 and $50 \%$.

Methods of strengthening the anchor support and calculating its characteristics of the anchor support of the mine workings are carried out in accordance with the value of the rock pressure. In turn, the rock pressure is determined taking into account the size and depth of the mine workings and the interface from the surface, the method and the parameters of their protection from the impact of cleaning operations, strength, fracturing and rock stability in the roof.

In conditions where the calculated displacements exceed $300 \mathrm{~mm}$, we calculate the parameters of the anchor support of the mine workings from the conditions for ensuring maximum roof displacements not $>300 \mathrm{~mm}$, while maintaining the workings on the boundary with the worked out space, conducting them in the crocheting and protecting the whole.

Depending on the behavior of the rock pressure, the installation density of the anchors in the roof is checked and, if necessary, increased from the condition of the required minimum density of anchorage installation depending on the stability of the immediate roof:

- For an unstable roof not less than 1 anchor per $1 \mathrm{~m}^{2}$.

- For a medium-stable roof not less than 0.7 anchor per $1 \mathrm{~m}^{2}$.

- For a stable roof no less than 0.5 anchor per $1 \mathrm{~m}^{2}$.

At the same time, in order to avoid overloading, in all workings and mattings at design roof offsets greater than $150 \mathrm{~mm}$, the anchors and reinforcing supporting supports must be compliant or with damped compliant elements crumpled under loads reaching 0.8 from the bearing capacity of the anchor.

For anchors with partial fastening along the length of the well, the compliance value of which should be:

- From $40 \mathrm{~mm}$ at displacements of $151 \mathrm{~mm}$.

- Up to $70 \mathrm{~mm}$ at offsets of $301 \mathrm{~mm}$.

- Fixed over the entire length - from 30 to $51 \mathrm{~mm}$. 
In the workings and mattings, the anchors must have a compliance not $<50 \mathrm{~mm}$ and with displacements not $>50 \mathrm{~mm}$, in the roof of which lie a coal seam and rocks that are dangerous to mountain impacts and emissions.

The main indicators affecting the parameters of the anchor support are: the calculated displacements and the expected loads on the anchor support.

Figure 1-4 shows the user interface of the program. The interface of the computer program is created in the Russian and Kazakh languages. At Figures 1-4 the version of the interface is presented in Russian (the decimal fraction is presented through a comma).
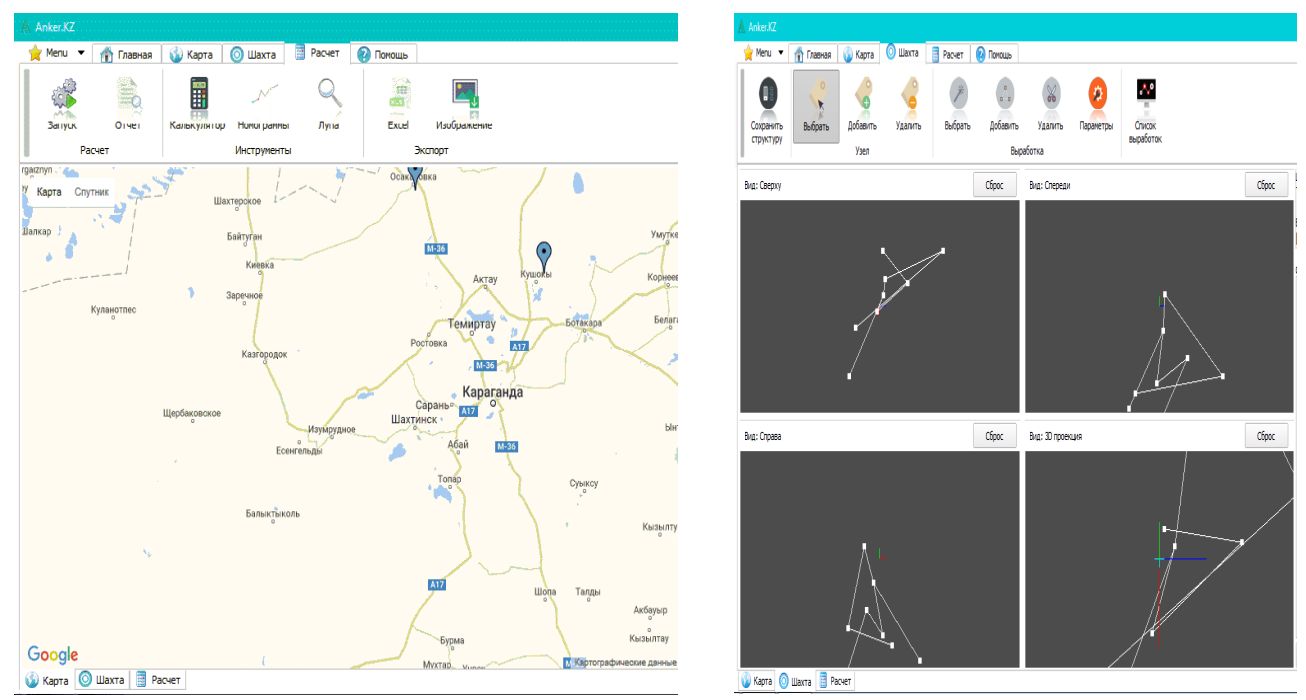

Fig. 1. Choice of mine and mine workings.

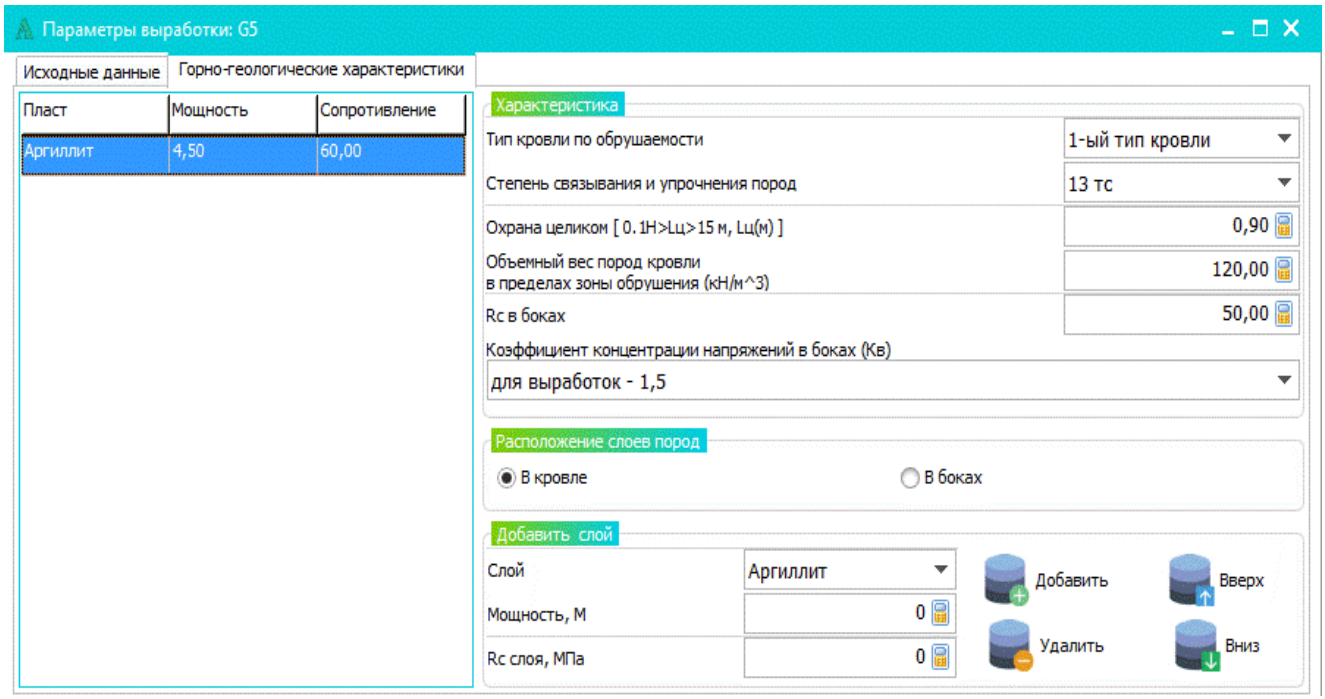

Fig. 2. Characteristics of the mine workings. 
Исходные данные Горно-геологические характеристики

\begin{tabular}{|c|c|c|}
\hline \multicolumn{3}{|l|}{ Параметры выработки } \\
\hline Наименование выработки & G5 & Расположение выработоки \\
\hline Ширина выработки, м & 5,00 凅 & Воздействие других выработок \\
\hline Высота выработки, м & 3,50 道 & Влияние других смежных \\
\hline Глубина выработки, м & 400,00 逐 & выработок на расстоянии \\
\hline Форма поперечного се & прямоугольная & выработки, м \\
\hline
\end{tabular}

\begin{tabular}{|l|}
\hline штреки, уклоны, бремсберги и сопряжения \\
\hline Одиночная выработка \\
\hline \hline 0 \\
\hline 15,00 凅 \\
\hline
\end{tabular}

\section{Вид выработки и условия ее поддержания}

- [Um] Проводимых в масссиве и поддерживаемых в продлолжение всего срока службы вне зоны влияния очистных работ

[Uц] Проводимых в массиве, а затем поддерживаемых в зоне влияния очистных работ

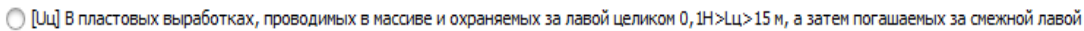

[Uп] В пластовых выработках, проводимых в массиве и погашаемых за лавой

[Uл] В пластовых выработках, проводимых в массиве, а затем охраняемых разрушающимся в выработанном пространстве целиком шириной 2-3 мощности пласта

[Uпр] В пластовых выработках проводимых в прическу к выработанному пространству

Fig. 3. Mining and geological characteristics.

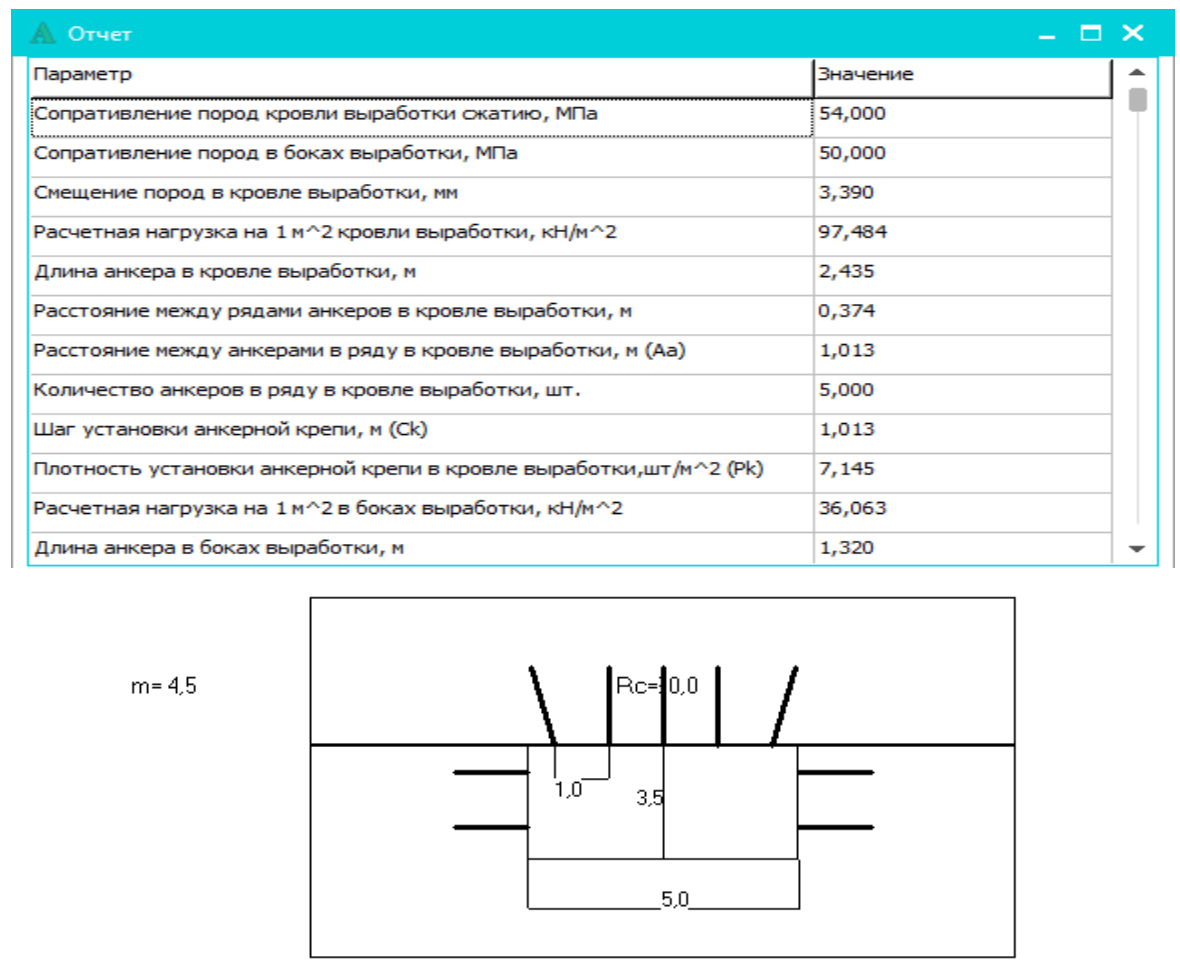

Fig. 4. Calculation result.

The following indicators are used as input data:

- Resistance of rocks to compression of the workings in the sides and roof of the mine to a height, Mpa.

- Volume weight of rocks, $\mathrm{kN} / \mathrm{m}^{3}$. 
- Coefficient of structural weakening.

- Thickness of the layers, $\mathrm{m}$.

- Working height and width, m.

- Shape of the section and depth of the deposit, $\mathrm{m}$.

- Type of generation.

- The influence of other excavations.

- Width of the lid, m.

- Method of calculation.

- Bearing capacity of the anchor support, kN.

- The length of the protruding part of the anchor, $\mathrm{m}$.

- Depth of penetration, m.

- Bearing capacity of rope anchors, $\mathrm{kN}$.

- The degree of fracture of rocks.

- Type of roofing.

- The degree of collapse of the roof rocks.

\section{Conclusion}

In order to establish the correctness of calculation of the anchor support parameters, using the developed program "Anker.KZ", the fastenings for the following developments of the UD mines of JSC "ArcelorMittal Temirtau" (Kazakhstan) were calculated:

1) Mounting chamber $231 \mathrm{~d} 6$ - in the mine "Shakhtinskaya".

2) Ventilation Bremsberg 4.03d6-1-Z mine them. Lenin.

3) Ventilation drift $41 \mathrm{k} 12-\mathrm{z}$ mine them. Kuzembaev.

4) Drainage drift 32k11-s mine "Abayskaya".

5) The second western ventilation slope $K 7$ mine them. Kostenko.

The thickness of the reservoir is $\mathrm{d} 6-5.4 \mathrm{~m}$ (fortress $f=1$ ). In the immediate top of the stratum there are argillites with a thickness of $0.44 \mathrm{~m}$ (strength $f=2.5$ ), with a capacity of 1.0 $\mathrm{m}$ (strength $\mathrm{f}=3.2$ ). Above there are siltstones $4.11 \mathrm{~m}$ thick (fortress $f=4.51$ ).

The shape of the cross section of the mine is rectangular. The working height is $3400 \mathrm{~mm}$, the working width is $5651 \mathrm{~mm}$. The depth of work is $471 \mathrm{~m}$.

According to the passport calculated by the technical department of the Shakhtinskaya mine, the length of the anchors is assumed to be $2.3 \mathrm{~m}$, the number of anchors in the row in the roof 7 in the sides 2 . The distance between the anchors in the row is $0.9 \mathrm{~m}$, between the rows of anchors is $0.74 \mathrm{~m}$.

As a result of calculations using the program "Anker.KZ" received the following values:

- Number of anchors in the row -7 anchors.

- The distance between the anchors in the row is $0.85 \mathrm{~m}$.

- The length of the anchor in the roof of the mine is $2.54 \mathrm{~m}$.

- The distance between the rows of anchors in the roof of the mine is $0.84 \mathrm{~m}$.

- The number of anchors in the row in the roof of the mine -7 anchors.

- The length of the anchor in the sides of the mine is $1.32 \mathrm{~m}$.

Comparison of the calculation results showed that the distances between the anchors calculated by the two methods are in satisfactory agreement. The length of the anchor calculated with the help of the program "Anker.KZ" is longer than the length indicated in the passport by $0.15 \mathrm{~m}$.

Analysis of the geological section along the production route showed that, at a length of $2.4 \mathrm{~m}$, the anchor is located in the argillite layer with a strength of $f=2.5$. 
At a length of $2.56 \mathrm{~m}$, the upper part of the anchor is located in the layer of argillite with a strength of $f=3.3$, which increases the efficiency of the anchor support. The number of anchors in the series, calculated by both ways is the same.

Ventilation Bremsberg 4.04d6-1-z is carried out on the upper layer of layer d6. The immediate roof of the reservoir in the area of production is represented by easily collapsible mudstones with a thickness of 0.3 to $7 \mathrm{~m}$, and a strength $f=2.5$. In the main roof of the layer, the siltstone is strong, difficult to fall, $f=4$.

The shape of the section is arched. Type of support - combined. The working height is $3735 \mathrm{~mm}$, the working width is $5570 \mathrm{~mm}$. The depth of the work is $650 \mathrm{~m}$.

According to the passport of fastening and carrying out for fixing the working, a combined support is adopted with the following parameters:

- Length of anchors $-2.4 \mathrm{~m}$.

- The distance between the anchors in the row is $0.81 \mathrm{~m}$.

- Distance between the rows of anchors $-0.74 \mathrm{~m}$.

- The number of anchors in the roof -7.7 anchors.

As a result of calculations using the "Anker.KZ" program, the following was received:

- The length of the anchor in the roof of the mine is $2.38 \mathrm{~m}$.

- The distance between the rows of anchors in the roof of the mine is $0.81 \mathrm{~m}$.

- The distance between the anchors in the row in the roof of the output is $0.75 \mathrm{~m}$.

- The number of anchors in the row in the roof of the mine is 7 .

- The length of the anchor in the sides of the mine is $1.31 \mathrm{~m}$.

Analysis of calculation results showed that the distances calculated by the program are slightly higher than the corresponding values of the passport. The number of anchors in the row is the same as the number indicated in the passport.

Based on the results of testing the computer program, the following conclusions can be drawn:

1) The program has a convenient intuitive interface that allows you to easily navigate when entering the source data.

2) The program takes into account the main conditions for carrying out mine workings.

3) The computer program allows you to reduce the time for calculating the parameters of the anchor support. On average, the calculation takes about 2-3 minutes.

5) As a result of the calculations, the program issues all the basic parameters of the anchor support.

6) The results of calculations satisfactorily coincide with the parameters adopted by the passport.

7) During the testing of the program failures, no critical errors were observed.

8) The ability to enter only one type of rock in the sides of the mine, which reduces the reliability of the results obtained when calculating the lining workings carried out by the mixed face.

\section{References}

[1] V. Demin, T. Isabek, V. Melnik, Controlling the stability of mine workings in difficult mining conditions (KSTU, Karaganda, 2016)

[2] V. Zhurov, Perfection of a technique of calculation of parameters of fastening of developments with allowance for mining technological factors, Thesis of the candidate of technical sciences (2010)

[3] Instruction on the calculation and use of anchor support in the mines of the Karaganda basin, (2008) 